\title{
Psychosocial Factors and Their Relationship to Work Amongst Workers in the Financial Sector
}

\author{
Roberta Zaninelli do Nascimento ${ }^{1}$, Milva Maria Figueiredo de Martino ${ }^{2}$, \\ Isabel Cristina Kowal Olm Cunha ${ }^{3}$, Cyro Rego Cabral Junior ${ }^{4}$ \\ ${ }^{1}$ Departament of Coletive Health, University Federal of Alagoas, UFAL, Maceió, Alagoas, Brazil \\ ${ }^{2}$ Departament of Nursing, University Estadual de Campinas, UNICAMP, Campinas, Brazil \\ ${ }^{3}$ Departament of Nursing, University Federal de São Paulo, UNIFESP, São Paulo, Brazil \\ ${ }^{4}$ Departament of Nutricion, University Federal of Alagoas, UFAL, Maceió, Alagoas, Brazil
}

Email address:

roberta.zaninelli@esenfar.ufal.br(R.Z.do Nascimento), isabelcunha@unifesp.br(I. C. K. O. Cunha)

\section{To cite this article:}

Roberta Zaninelli do Nascimento, Milva Maria Figueiredo de Martino, Isabel Cristina Kowal Olm Cunha, Cyro Rego Cabral Junior. Psychosocial Factors and Their Relationship to Work Amongst Workers in the Financial Sector. American Journal of Nursing Science. Vol. 9, No. 4, 2020, pp. 285-289. doi: 10.11648/j.ajns.20200904.31

Received: June 13, 2020; Accepted: June 29, 2020; Published: July 30, 2020

\begin{abstract}
Introduction: The evolution of work characteristics and the work sector may bring physical and psychological consequences to the health of workers. Objective: To analyze the demand for control amongst workers in the financial sector. Method: This was an exploratory, cross-sectional, quantitative study, which included 39 workers from a company in the financial sector based in São Paulo. We used the short form of the Demand-Control-Support Questionnaire (DCSQ). Results: There was a prevalence of low demand and control amongst the 39 workers interviewed. The mean age was 30 years. The results obtained by categorization demonstrated that the coexistence of low demand and low control were present amongst the workers of this financial sector and it is known that the interaction of two factors, termed passive work and intermediate health risk, are considered to induce a decline in the general activities of an individual. Conclusion: The presence of psychosocial factors at the workplace may favor apathy at work, a lack of interest and low production.
\end{abstract}

Keywords: Psychosocial Aspects, Financial Sector Workers, Worker Health

\section{Introduction}

The "working class" concept, which originated in Europe during the nineteenth century, has been increasingly questioned over recent decades. A number of historians and sociologists have observed that the dividing line between "free" wage labor, self-employment and non-free labor, is in fact unclear, and the differences between urban and rural work should not be considered in an absolute form [1]. Many struggles had to be faced before arriving at the narrow concept in the nineteenth century of an employee as a proletariat, as cited by Marx and other authors, and which originated in the segmentation of Haitian slaves in 1791, and was the "first successful workers' revolt in modern history, [...] What was left behind was national and partial: the English working class, the black Haitian, the Irish diaspora." [1].

During the 1980s, in advanced capitalist countries, profound transformations took place in the world of work, both in the forms of inserting the productive structure and of union and political representations. There were also constant transformations in labor relations, from which it may be said that the class-that-lives-from-labor suffered the most acute crisis of the century, affecting not only its materiality, but experiencing profound repercussions in its subjectivity, and in the interrelationship of these levels that affected its way of being [1]. It lived in the world of production with a set of experiments, more or less intense, more or less consolidated, more or less tendential, embryonic, except that Fordism and Taylorism were no longer the only possibilities and became intertwined with other processes (Neo-Fordism, Neo-Taylorism, Post-Fordism), even in the Kalmar region which resulted in Kalmarism, in Silicon Valley in the US, in a region of Germany etc [1].

New labor processes emerged, where the chronometer and 
both mass and serial production were "replaced" by flexible production, and by "flexible specialization", by new patterns of seeking productivity, by new ways of adapting production to logic [1]. Part of the effects of this flexibilization process, as indicated by various surveys, indicate the high incidence of occupational accidents, including fatal accidents, in addition to work-related illnesses, particularly those related to osteoarticular injuries and mental disorders [2].

Empirical evidence has generally suggested that job demands may trigger stress reactions and render a negative impact on the mental and physical health of employees while working [5]. It was observed that resources were associated with positive health effects and promoted employee involvement in the work [5]. Important events that have occurred during the history of mankind have led to new forms of work organization and management at work, one of which is outsourcing, which is rooted in the industrial revolution, and over the past 40 years, outsourcing has been incorporated into the processes of productive restructuring, such as Japanese Toyotism - its main inspiration. As this pattern of westernized work organization, subcontracting, or outsourcing, has occupied a central position, thereby becoming added to the globalization of capital, and outsourcing has therefore been viewed as the preferred, most efficient manner of capital, with the aim of making work more flexible, as a symbol of business modernity and the new basis for global competitiveness $[2,1]$.

In Brazil, the old phenomenon of outsourcing was rooted in agricultural work, but during Brazil's urban industrial development, with the installation of factories, outsourcing came to occupy a secondary position. However, with the emergence of durable-goods factories (such as the automobile industry), outsourcing became part of the production structure, and with the phenomenon of economic and financial globalization and neoliberal policies that began in the early 1990s, outsourcing was no longer peripheral and is currently present in all types of companies: in industry, public and private services, in commerce, in construction, i.e., in all types of work [3].

Work has been categorized according to the services and occupations, into the so-called gray-collar workers, who occupy positions in administrative services and industrial occupations (also involving administration), and blue and gray collar workers, defined by Stevenson, as an indicator of different occupational demands and hierarchies, as defined below [4]:

Blue collar workers - occupations defined in processes/manufacturing; gray collar workers - health workers, activities classified in Brazil as a means (cleaning, construction, security, civil construction workers, and porters) and other workers such as hotel, logistics and industry services; and white collar workers - office work, social activities and teachers [4].

Research has indicated that the organization of work may bring paradoxical consequences for the physical and psychological integrity of individuals. This is because, on the one hand, it may be seen as a productive activity that provides an identity to the worker, with a fundamental role that guarantees their health, and yet on the other, it may acquire a sense of something harmful, something conducted in precarious conditions with no opportunities for professional development, and that may contribute to workers becoming ill, either due to a workaholic compulsion, or to non-work and unemployment [6].

An increase in the evidence of an association between job insecurity and worker health has been described in the literature, demonstrating that they may cause psychological distress, physical symptoms and low self-esteem. Working conditions, organizational and social structures, and individual characteristics may also be related and thereby increase the risk of accidents at work; $[7,6]$.

Accidents at work may be influenced by aspects of the immediate work situation such as: machinery, tasks, the technical or material environment, but also by the work relationships, organizational culture and worker fatigue [7] The work environment is therefore a reservoir of various stressors, both physical and psychologica 1 [6] With the changes that have taken place across the world, there is currently a need to understand the risk factors for occupational accidents, and the new problems arising from other risks, such as personal isolation when people work from home [6].

Industrial accidents at work are more frequent when compared to other sectors. In the US, in 2010, the highest number of fatal accidents occurred in civil construction; in Brazil, accidents at work represent the greatest threat to the health of workers, in addition to being complex and multi-causal phenomena, and which may also reveal a dysfunction in management and work organizations [8].

A number of epidemiological studies have reported that psychosocial factors at work are linked to the incidence of cardiovascular disease, decreased immune responses, high blood pressure, depression, and general well-being [8, 9].

Thus, our main question was: "Are psychosocial factors present and do they interfere in the daily work of workers in the financial sector?". To answer this question, the main objective of the study was to compare the psychosocial variables amongst workers in the finance department of a company in São Paulo.

\section{Method}

This was an exploratory, cross-sectional study, with a quantitative approach, amongst workers in the financial sector. The study was carried out in a company in the state of São Paulo, founded almost 27 years ago, with headquarters in the city of São Paulo. In 2018, the company had an average of 600 workers, working on different shifts and with different functions. They were chosen using a non-probabilistic sampling technique, where the questionnaires were distributed by email through the Survey Monkey platform. Thirty-nine workers participated, randomly selected through a free mathematical program available on the Internet amongst the 5 directorates. Workers who were on vacation, medical leave or maternity leave were excluded. Hence, 39 individuals belonging to the day and night shifts constituted the studied sample. 
Data was collected from May 2018 to June 2018.

The workers who responded to the questionnaires worked in various activities in the financial sector, including information technology, financial control, advocacy, communications, administrative and technical assistance.

This research was conducted in accordance with the guidelines and regulatory standards set out in Resolution 466/12 from the National Health Council [10](National Health Council 2012), and was approved by the Institutional Research Ethics Committee under CAAE 69304117.7. 0000.5505. All participants signed the informed consent forms.

The Spearman's correlation coefficient [12] was used for correlations between quantitative variables and the Student t-test for comparisons with quantitative variables, in addition to the non-parametric Mann-Whitney test [12]. For all analyzes, a significance level of $5 \%$ was considered. The statistical software R 3.6.2 [11] was used.

To assess and compare the psychosocial aspects of workers in the financial sector, we used the short form of the demand-control-support questionnaire (DCSQ), the Job Strain Model which contains 17 multiple choice questions subdivided into three scales: I - control at work and decision making: six questions regarding work - issues related to control at work and questions on decision making; II - demand at work: five questions on demand at work (these are concerned with time and the speed of doing the job), and III social support in the work environment: six questions on social support that workers receive in their work environment [12].

To calculate the instrument, the answers are formed by four optional items, in Likert scales that varied from 1 to 4 points. The scores were obtained in two manners: one - quantitatively, in which the scores were obtained by adding the items of each dimension, and ranged from 5-20 (demand) and 6-24 (control and social support). High demand, high control and high social support were categorized with values below the median of 39 respondents $(11,11$ and 22). The second manner was according to the median point of the scales, i.e., the scores were obtained by adding the items of each dimension and ranged from 5-20 (demand) and 6-24 (control and social support). High demand, high control and high social support were categorized in individuals with scores below the median point of the scale 12.5, 15 and 12.5; low demand high control make up low demand, high demand and high control - high demand low control active work - high demand, low demand low control passive work observed amongst workers in the financial sector surveyed [13].

Cronbach's Alpha was calculated for the variables demand, control and social support in order to provide greater credibility to the research.

\section{Results}

Table 1 presents the mean values and respective p-values obtained by the variance analysis for each of the variables analyzed as a function of the directorate factor.
Table 1. Means values for the domains demand, control and social support amongst the entre as directorates.

\begin{tabular}{lllllll}
\hline \multirow{2}{*}{ Domain } & \multicolumn{9}{l}{ Directorate } & & \multirow{2}{*}{ p-value } \\
\cline { 2 - 6 } & $\mathbf{1}$ & $\mathbf{2}$ & $\mathbf{3}$ & $\mathbf{4}$ & $\mathbf{5}$ & \\
\hline Demand & 11.37 & 11.50 & 10.64 & 11.40 & 10.14 & $0.237 \mathrm{~ns}$ \\
Control & 9.25 & 11.00 & 10.73 & 12.80 & 10.71 & $0.127 \mathrm{~ns}$ \\
Social Support & 20.00 & 20.25 & 18.55 & 20.80 & 18.71 & $0.493 \mathrm{~ns}$ \\
\hline
\end{tabular}

Thus, no significant differences were observed ( $\mathrm{p} \geq 0,05)$.

Table 2. Distribution of workers according to the classification high/low demand, control and social support.

\begin{tabular}{llll}
\hline Variables & Categorization & $\mathbf{n}$ & $\mathbf{\%}$ \\
\hline \multirow{2}{*}{ Demand } & Low & 39 & 100.00 \\
& High & 0 & 0.00 \\
\multirow{2}{*}{ Control } & Low & 39 & 100.00 \\
\multirow{2}{*}{ Social Support } & High & 0 & 0.00 \\
& Low & 100 & 100.00 \\
& High & 0 & 0.00 \\
\hline
\end{tabular}

Source Demand - Psychological demands. $\mathrm{C}=$ Control demand.

All workers in the financial sector were categorized into low demand control and social support (values below the midpoint previously described in the methods).

In addition to the distribution observed in Table 1, the work of the participants from the financial sector, according to the quadrants, in the control demands model, $100 \%$ presented themselves in passive work according to Table 3, a harmful job for the worker.

Table 3. Distribution of workers according to the categories of the control demands model - SP, 2018.

\begin{tabular}{llll}
\hline Variables & Categorization & n & \% \\
\hline Passive Work & $\mathrm{D} \downarrow \mathrm{C} \downarrow$ & 39 & 100.00 \\
Low Demand & $\mathrm{D} \downarrow \mathrm{C} \uparrow$ & 0 & 0.00 \\
Active Work & $\mathrm{D} \uparrow \mathrm{C} \uparrow$ & 39 & 100.00 \\
High Demand & $\mathrm{D} \uparrow \mathrm{C} \downarrow$ & 0 & 0.00 \\
Social Support & Low & 100 & 100.00 \\
& High & 0 & 0.00 \\
\hline
\end{tabular}

Source: D - Psychological demands. C= Control

For a greater reliability in our studies, we used Crobach's Alpha, and the control is further from 1, so the result expresses less reliability when compared to Demand and Social Support (Table 4).

Table 4. Crobach's Alpha amongst the workers in the finance department.

\begin{tabular}{ll}
\hline Questionnaire & Alfa \\
\hline Demand & 0.75 \\
Control & 0.58 \\
Social Support & 0.80 \\
\hline
\end{tabular}

Source: Nascimento 2018

\section{Discussion}

The current conjuncture of active life is characterized by incessant rhythms, an intensification of production regimes and urgent changes. In addition to these structural changes, the current economic crisis places increasing pressure onto 
employers and workers in order to maintain appropriate levels of competitiveness. Many of these changes offer opportunities for development, but at the same time these workers must adapt to rapid changes in working conditions and psychosocial factors in the labor market. Thus, appropriate and comprehensive approaches are needed to address issues related to work stress in the workplace. In addition, psychosocial factors (including work stress and mental health) have been important issues in the field of occupational health, both in developed and developing countries [14, 13, 15].

A research, conducted amongst different types of workers, denominated blue, gray and white-collar workers, each of which has been described above, focused on verifying the existing differences in work environments, and which may render a significant influence on the health conditions of each worker. The findings will be valid for further research [16]

Amongst the workers of this financial sector, the results obtained by the categorization demonstrated that the coexistence of low demand and low control are the same findings encountered between injured and healthy construction workers. It is known that the interaction of the two factors - called passive work, and intermediate health risk - are considered to induce a decline in an individual's general activities $[17,18]$.

For many, work is a social activity, a crucial source of feedback and may be a central component of personal identity, thereby generating, or not, health and quality of life. Thus, working conditions may enforce a particularly prominent influence on emotions, self-esteem, and identity. Although work is normally assumed to promote health, the net effect on mental health depends on the psychosocial quality of work. However, workers, as a result of the exhaustive routine in certain segments, 37,5 hour per week, such as health workers, become ill from physical diseases and stress and fatigue $[15,18]$.

In this study, there was a prevalence of males in certain professions, much like civil construction, drivers truck, which is different from a study conducted by Bonsaken, in which there were more females, and in a study by Silva where there was no statistically significant difference [19]

The mean age of workers in the financial sector was 30 years, while in another Brazilian study carried out in 2008 at a state bank, the mean age was between 50 and 59 years old [16].

With regard to the psychosocial aspects that exist amongst workers in the finance department, the research demonstrated that social support was assessed as being better, although it was below average, noting that there was little social support amongst these workers.

Amongst the workers of this finance department, the results obtained by the categorization demonstrated that the coexistence of low demand and low control were also present between the injured and healthy construction workers, and it is known that the interaction of the two factors - called passive work, intermediate risk to health _ are seen as inducing a decline in the individual's general activities [19].

Therefore, the worker feels apathetic, either due to the absence of new challenges or the absence of decision-making. Low control may be translated as a lack of autonomy in the process and may be a psychosocial risk factor and, consequently, for the appearance of depressive symptoms. The low demand present in the study $[17,18,20]$.

The absence of social support may favor the onset of depressive symptoms. In this research, low social support amongst workers was observed. In addition to low control, another risk factor that may be added to the psychosocial diseases is the low participation in decision making and the lack of support by superiors, which may be assessed as such and may increase anxiety, stress, mental fatigue and the likelihood of accidents. However, when workers are part of the decisions, they feel valued and part of the process [20].

After the text edit has been completed, the paper is ready for the template. Duplicate the template file by using the Save As command, and use the naming convention prescribed by your conference for the name of your paper. In this newly created file, highlight all of the contents and import your prepared text file. You are now ready to style your paper; use the scroll down window on the left of the MS Word Formatting toolbar.

\section{Acknowledgements}

With regard to the psychosocial environment, amongst workers in the financial sector, the present study has made it possible to identify that social support obtained a better score when compared to control and demand, although it was below average. As a consequence, social support, even with below-average values although higher when compared to others, was nonetheless positive, since workers are able to count on one another, giving each other support and thus providing a healthier work environment.

The predominant characteristic observed in this research was that of low demand and low control, i.e, passive work, thereby constituting a less harmful situation. This in turn, may have an influence over mental disorders, discouragement, a lack of belonging to a team, presenteeism and absenteeism due to the low level of autonomy in the process of work, little work and a lack of social support, which would be one of the stimulating factors that enables workers to have interaction, and trust between the members of the work team.

Therefore another study that the authors intend to reserach in another time that is Demand Demand-Induced Strain Compensation Model, tha can help in another studys [21]

\section{References}

[1] Antunes R., Praun L. A. (2019) Bet be on the rublo: labor and Social Security -the doublé face of a project. Legal magazine work and human developers. 56-81. https://doi.org/10.33239/rtdh.v2i1.43

[2] Antunes R., Praun L. Goodyear to work, essas on metamorphosis and centrality of the world of work. 16 ed. 2 imp. Editora Cortez, São Paulo, São Paulo, pp

[3] Druck G. (2016) Terceirização desenfreada no Brasil: mais riscos precarização e de saúde para os trabalhadores. Cad. Saúde Pública http://dx.doi.org/10.1590/0102-311X00146315 
[4] Burgess S., Junne F., Rothermund E., Zipfel S., Gundel H., Rieger MA, Michaelis M. (2019) Common mental disorders through the eyes of German employees: attributed relevance of work-related causes and prevention measures assessed by a standardised survey Int Arch Occup Environ Health 92 (6): 795-811. https://doi: 10.1007/s00420-019-01414-7

[5] Mette J., Garrido MV, Preisser AM, Harth V., Mache S Linking quantitative demands to offshore (2018) wind workers' stress: do personal and job resources matter? A. structural equation modelling approach. BMC Public Health. 18-934. https://doi.org/10.1186/s12889-018-5808-8

[6] Wirth T., Mette J., Nienhaus A., Schillmoller, Harth V., Mache S. (2019) "This Isn't Just about Things, It's about People and Their Future": A Qualitative Analysis of the Working Conditions and Strains of Social Workers in Refugee and Homeless Aid. Int J Environ Res Public Health 16 (20): 3858. https:// doi:10.3390/ijerph16203858

[7] Jonge DeJ, Peeters MCW, Taris TW (2019) Feeling Vital or Fatigued? Relations with Demands and Resources in a University Context. Int J. Environ Res Public Health 16 (16): 2893. https://doi: 10.3390/ijerph16162893.

[8] Alexopoulos EC, Argyriou E., Bourna V., Bakoyannis G (2015) Reliability and Validity of the Greek Version of the Job Content Questionnaire in Greek Health Care Workers. Safety and Health at Work. 6 (3): 233-239. https://doi:10.1016/j.shaw.2015.02.003

[9] Heo Y. -S., Leem J. -H., Park S. -G., Jung D. -Y., Kim H. -C. (2015) Job stress as a risk factor for absences among manual workers: a 12-month follow-up study. Industrial Health 53 (6): 542-552. https://doi:10.2486/indhealth

[10] National health council. (Brazil) (2012) Resolution n 466, de december 12. Brasília. http://conselho.saude.gov.br/resolucoes/2012/Reso466.pdf.

[11] R Core Team (2019). R: A language and environment for statistical computing. R Foundation for Statistical Computing, Vienna, Austria. URL https://www.R-project.org/.https://pt.surveymonkey.com/

[12] Pagano M, Gauvreau K. Princípios de Bioestatística. São Paulo: Thomson; 2004. Livr
[13] Alves MGM, Braga VM, Faerstein, E., et al (2015). Model demanda work stress control: considerations on different watts to operacionalize the exposure variabile. Public Health notebook. $\quad 31 \quad$ (1): 208-212. https://doi:org/10.1590/0102-311X00080714

[14] Lee K., Kim I. (2018). Job Stress-attributable Burden of Disease in Korea. J. Korean Med Sci. 1-10. https://doi.org/10.3346/j

[15] Sieurin J., Andel R., Tillander A., Valdes EG, Pederson NL, Wirdefeldt K. (2018). Occupational Stress and Risk for Parkinson's Disease: A. NationwideCohort Study. Wiley Moviment Disorders. 1456-1464 http://doi.org/10.1002/mds.27439

[16] Bonsakse, T. Thørrisen M, Skogen, JC, WagoAa, R Who reported having a high-strain job, low-strainjob, active joband passive job? The WIRUS Screening study. PLOSONE| https://doi.org/10.1371/journal.pone.0227336December3

[17] Fan, W, Moen P. Kelly E, Hammer, LB, Berkman LF. Job Strain, Time Strain, and Well-Being: A Longitudinal, Person-Centered Approach in Two Industries. J Vocat Behav. 2019 Feb; 110 (Pt A): 102-116. doi: 10.1016/j.jvb.2018.10.017. Epub 2018 Oct 31.

[18] Zarpelao RZN, De Martino MMF, Cunha ICKO, Vieira CMS (2018) Psychosocial Factors And Their Relation Between Work Accidents Among Outsourced Construction Workers. IJPERA. 67-71. http://dx.doi.org/ 10.3346/jkms.2010.25.S.S87

[19] Silva LS Barreto SM (2012) Stressful working conditions and poor self-rated health among financial services employees. Rev. Saúde Pública 407-416.

http://dx.doi.org/10.1590/S0034-89102012005000023

[20] Tomei G., Capozzella A., Rosati MV, Tomei F., Rinaldi G., Chighini A., et al (2015) Stress e infortuni sul lavoro. Clin Ter 166 (1): e 7-22.

[21] Jonge, Jd, Peeters C. W. M, Taris, WT. Feeling Vital orFatigued? Relations with Demands and Resources in a University Context. International Journal of Enviromental of Research at Public Health., 2019, 2-24. 